\title{
FATIGUE OF THE SWEAT GLANDS
}

\author{
By JØRN HESS THAYSEN AND IRVING L. SCHWARTZ
}

\author{
(From the Hospital of The Rockefeller Institute for Medical Research, New York, N. Y.)
}

(Submitted for publication July 14, 1955; accepted July 28, 1955)

The rate of sweat secretion has been shown to decrease during prolonged exposure to heat (1-3). This phenomenon has practical importance in the etiology of heat stroke, since the evaporation of sweat is the only significant means for dissipating heat when the environmental temperature equals or exceeds the body temperature.

It is not known whether this decrease in sweating rate is due to a failure of the sudomotor center or to an exhaustion of the peripheral glandular units. The present investigation was undertaken in an attempt to answer this question. The results indicate that the decrease in sweating rate is due primarily to fatigue of the secretory mechanism of the glands. Apparently sweating can continue indefinitely at the same rate only as long as the demand upon the secretory mechanism does not exceed the capacity of the simultaneous restorative processes. Whenever the demand upon the secretory mechanism exceeds restorative capacity the rate of sweating decreases.

\section{PROCEDURE}

Four young, un-acclimatized, healthy males served as subjects for the experiments which were conducted during the winter months. Sweating was stimulated in a hot room, temperature $40^{\circ}$ to $45^{\circ} \mathrm{C}$., relative humidity 60 to 90 per cent. The carbon dioxide and oxygen concentrations of the air were controlled and kept constant at normal values prevailing outside the gas-tight chamber. The subjects entered the room nude except for a pair of light shorts and remained at rest lying uncovered on top of a bed during the entire experiment. Room temperature and rectal temperature were recorded every 30 minutes.

The total amount of sweat secreted from the entire body surface was estimated at accurately timed intervals of 30 to 60 minutes' duration. The subject removed his shorts. His skin was dried thoroughly with towels and body weight measured to the nearest $50 \mathrm{gm}$. Water, approximately at body temperature, was imbibed in amounts equivalent to the loss in body weight; sodium chloride was taken to replace an estimated average loss of $50 \mathrm{mEq}$. of sodium per liter of sweat produced. The total amount of sweat secreted in any period was calculated from the weight loss with corrections for water intake and urine flow. The insensible water loss from the skin and through the expired air and the metabolic weight loss were taken into account and did not introduce a significant error into this calculation at the sweating rates which prevailed in these experiments.

Local collections of sweat, using special collection chambers (4), were obtained from the ventral surfaces of the forearms. The sweat was absorbed into filter paper discs and the rate of flow calculated by the weight increment of the disc during exactly timed periods of 20 to 30 minutes' duration.

Prints of the sweating areas were obtained and analyzed by methods previously described (5). In brief, paper impregnated with iodine was placed in special holders and pressed against the skin of the local collection areas for timed periods of 1 to 10 seconds. The water emerging from the sweat glands reacted with the iodine and starch of the paper to form distinct blue dots. These were counted under a dissecting microscope (coefficient of variation for replicate counts $=2$ per cent), and classified by size with increments in diameter of $0.04 \mathrm{~mm}$. The dispersion of glandular activity was shown by the distribution of the logarithm of the dot diameter, this distribution being chosen because it is independent of the absolute rate of sweating and the length of exposure of the printing paper (5).

The reactivity of the sweat glands to substances with a stimulating or inhibiting effect on sweat secretion was tested by injection of a minute dose at the site of sweat collection on the forearm. The symmetrical site on the other extremity served as a control, since the amount of drug injected at the test site was too small to elicit systemic effects.

\section{RESULTS}

The rate of sweating decreased and the rectal temperature rose after 3 to 6.5 hours of profuse sweating.

The decrease in sweat flow after long exposure to heat was observed in four experiments lasting 5 to 6.5 hours. As shown in Figure 1 the total output of sweat rose to a maximum value by the third to fifth hour, and then decreased to 30 to 60 per cent of the maximum despite an increase in temperature of the hot room. Flow rates measured with collecting chambers on the forearms, showed a rise and fall that paralleled the general trend. Air temperature and rectal temperature 


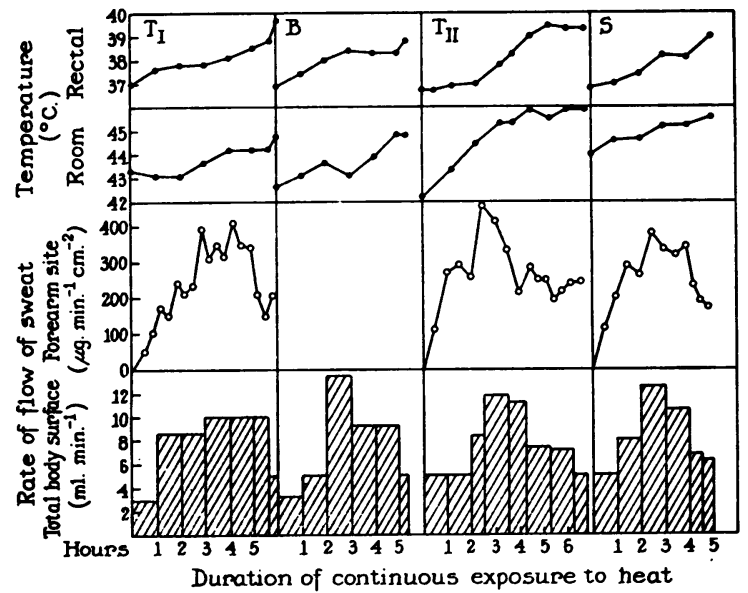

Fig. 1. The Rates of Sweating (Total Body Surface and Local Collection Sites on the Forearms), RoOm Temperatures and Rectal Temperatures are Shown in Relation to Time Spent in a Hot Room (Four Experiments, Three Subjects)

rose throughout the course of each experiment, showing that the decrease in sweating rate was not due to a decrease in primary stimulus.

The decrease in the rate of sweating was mainly due to a decrease in the mean flow per gland and less to a decrease in the number of functioning glands; the relative activities ${ }^{1}$ of the sweat glands remained unchanged throughout the heat exposure. This phenomenon was demonstrated in experiment $T_{\text {II }}$ by simultaneous collections of sweat and registrations of the number of functioning glands within the same area of skin of the forearm. As shown in Figure 2 and Table I, the initial increase in sweating rate was effected chiefly by an increase in the mean flow per gland and to a lesser extent by increase in the number of functioning glands. The subsequent fall in the rate of sweating was, likewise, more due to decrease in the mean flow per gland and less to decrease in the number of functioning glands (Table I). The relative activities of the glands remained

1 The term relative activity denotes the fraction of the total flow from an area contributed by each of the individual glands. Therefore it refers to the secretory activity of any gland relative to the secretory activity of every other gland as well as the field as a whole. For example a small gland in a field of 100 glands may contribute 0.1 per cent of the total outflow, an average gland 1 per cent, and a large gland 10 per cent; these relative contributions may remain the same or change with varying physiologic or pathologic conditions. unchanged despite the changes in mean output, indicating that each of the individual units fatigued at the same rate. The relative contributions of small and large glands were similar at all rates of flow (Figure 2).

The output of sweat, following intradermal injection of Mecholyl was diminished by preliminary prolonged reflex sweating. In one of the above experiments $\left(T_{I}\right)$ Mecholyl ( $\beta$-methylacetylcholine hydrochloride), $2 \mathrm{mg}$. in $0.5 \mathrm{ml}$. isotonic saline, was injected intradermally at the site of local sweat collection on the forearm after a period of six hours of profuse reflex sweating. The output of sweat was compared to the average output at the same site when stimulated with Mecholyl under "resting conditions."

It will be seen from Figure 3 that the reactivity of the sweat glands to this standard dose of cholinergic drug was significantly decreased by preliminary prolonged reflex sweating. Repetition of this experiment yielded identical results.

Intradermal infiltration with atropine, sufficient to block sweat secretion for a period of 4.3 hours, was followed by hypersecretion of sweat as compared to a symmetrical site that had continued to function throughout a prolonged exposure. Sweat collection chambers were glued to symmetrical

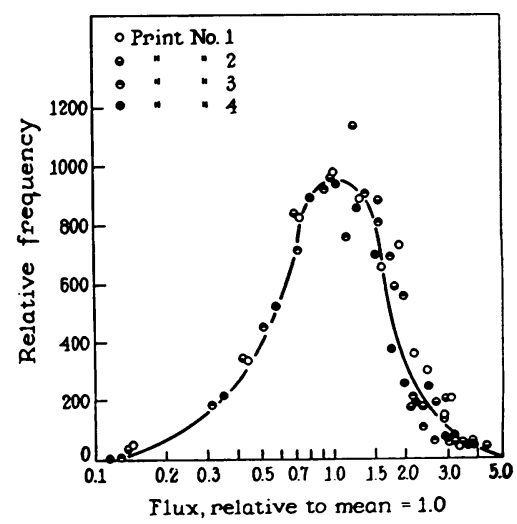

Fig. 2. The Frequency Distribution of the Logarithm of Dot Diameters of Four Prints Taken from the Same Forearm Site at Various Times during Exposure to Heat

On each print the number of glands was counted and classified by increments in diameter of $0.04 \mathrm{~mm}$. The logarithms of the dot diameters were used and the distributions of the four prints shifted to a common mean so that each distribution is independent of the sweating rate and the printing time. 
sites on the ventral surfaces of the forearms. Atropine sulfate $(0.005 \mathrm{mg}$. in $0.5 \mathrm{ml}$. isotonic saline) was injected intradermally at the collection site on the left arm. Thereafter the subject entered the hot room where he remained for 6.8 hours. The blocking effect of the atropine was checked by making prints with iodinated paper. Whenever the faintest trace of sweating was observed, atropine was reinjected (usually every 30 to 40 minutes). These injections had no systemic effect as judged by the overall sweat secretion and the rate of sweating from the symmetrical site on the right forearm. The atropine injections were repeated eight times, blocking the secretion of sweat at the collection site on the left forearm for a total of 4.8 hours. Then the atropinized area was permitted to sweat freely for the

TABLE I

Relation of the number of functioning glands to the mean sweating rate from an area of forearm skin

1 inch in diameter at various times during exposure to heat

\begin{tabular}{|c|c|c|c|c|}
\hline \multirow[b]{2}{*}{$\begin{array}{c}\text { Print } \\
\text { number }\end{array}$} & \multirow{2}{*}{$\begin{array}{c}\text { Time } \\
\text { after } \\
\text { entering } \\
\text { hot room } \\
\text { hrs. }\end{array}$} & \multirow[b]{2}{*}{$\begin{array}{l}\text { Gland } \\
\text { count }\end{array}$} & \multicolumn{2}{|c|}{ Mean sweating rate } \\
\hline & & & $\begin{array}{l}\text { From local } \\
\text { skin area } \\
\text { mg./min. }\end{array}$ & $\begin{array}{l}\text { Mean flow } \\
\text { per gland } \\
\text { Mg./min. }\end{array}$ \\
\hline $\begin{array}{l}1 \\
2 \\
3 \\
4\end{array}$ & $\begin{array}{l}0.75 \\
2.25 \\
3.75 \\
5.25\end{array}$ & $\begin{array}{l}602 \\
690 \\
516 \\
480\end{array}$ & $\begin{array}{l}1.02 \\
1.74 \\
0.82 \\
0.73\end{array}$ & $\begin{array}{l}1.69 \\
2.95 \\
1.59 \\
1.52\end{array}$ \\
\hline
\end{tabular}

remaining 2 hours of the stay in the hot room. Sweat was collected in 30-minute periods from the collection site on the right arm starting 15 minutes after the subject entered the hot room and ending 6.5 hours later. For the last 2 hours sweat collections were made in 20 -minute periods from both forearm sites.

Figure 4 shows the results. The glands on the left forearm which had been kept inactive for the first 4.8 hours of the experiment showed a definite hypersecretion as compared to the glands on the right forearm that had continued to function throughout the entire heat exposure.

It was considered possible that repeated injections of atropine caused the glandular cells to become sensitized to the action of acetylcholine. This possibility was excluded by the finding that a skin area, pretreated by repeated intradermal injections of atropine and then allowed to rest

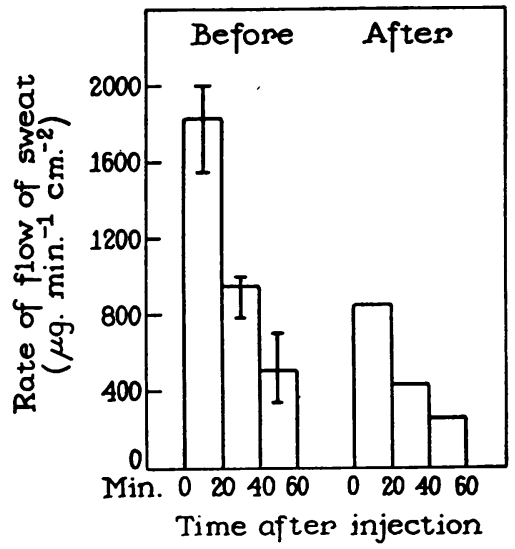

Fig. 3. The Reactivity of the Sweat Glands to a Standard INTradermal Stimulus ( $\beta$-MethylacetylCHOLINE HYDROCHLORIDE) UNDER RESTING CONDITIONS (Left) and - Following 6 Hours of Profuse Reflex Sweating (Right)

The columns to the left represent the mean of eight determinations; the vertical lines represent the range of variation.

for 45 minutes after the last injection of atropine, showed no greater response to intradermal Mecholyl than a control area which had received no pretreatment.

Repeated intradermal injections or a constant intradermal infusion of Mecholyl evoked decreasing outputs of sweat until a refractory state was

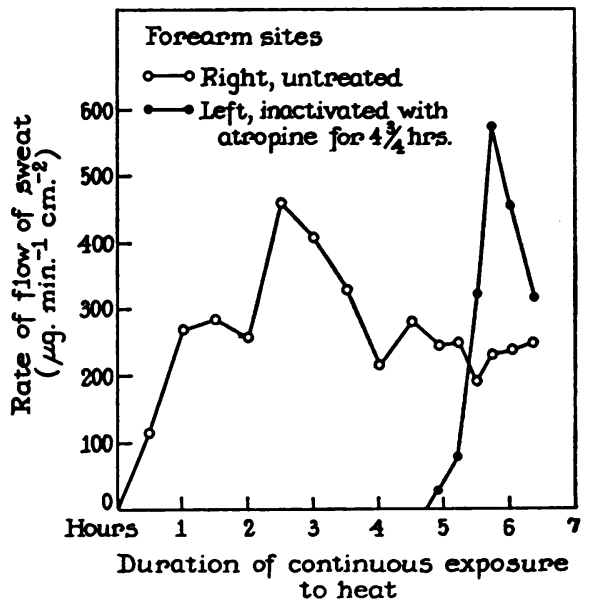

Fig. 4. Comparison between the Flows of Sweat From. Two Areas of SkIN

One area (right) has continued to function throughout a 6.8-hour heat exposure; the other area (left) has been kept inactive for the first 4.8 hours of the heat exposure by intradermal infiltration with atropine. 


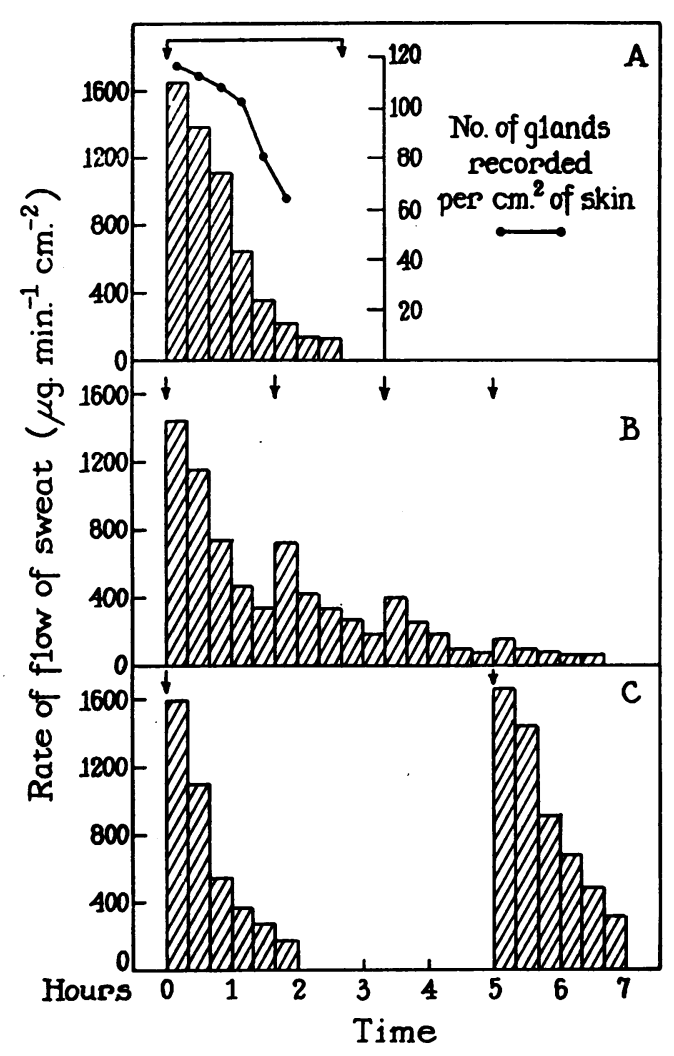

Fig. 5. A. The Flow of Sweat and the Number of Functioning Glands Following a Constant IntraDeRmal Infusion of Mecholyl at the Rate of $50 \mu \mathrm{g}$. per Minute. B. The Flow of Sweat Following Four INTRADERMAL INJECTIONS OF MEChOLYL, 2 MG. IN 0.5 ML. of Isotonic Saline, at Intervals of 100 Minutes. C. The Flow of Sweat Following Two Intradermal INJECTIONS OF MEChOLYL, 2 MG. IN $0.5 \mathrm{ML}$. OF IsotoNiC Saline, Separated by an Interval of 300 Minutes

reached; as in the case of generalized reflex sweating the decrease in the rate of sweating was primarily due to a decrease in the mean flow per gland and less to a decrease in the number of functioning glands. All experiments were carried out at the same skin sites on the forearm of the same subject resting at room temperature, $20^{\circ}$ to $25^{\circ} \mathrm{C}$. Mecholyl, $2 \mathrm{mg}$. in $0.5 \mathrm{ml}$. isotonic saline, was injected intradermally at intervals of 100 and 300 minutes; or a constant intradermal infusion of Mecholyl was given at a rate of $50 \mu \mathrm{g}$. per minute. Collections of sweat and prints of the number of functioning glands were made in the usual manner. The results are shown in Figure 5. It will be seen that a full response to a second injection of Mecholyl was obtained when the interval between two injections was 5 hours (Figure 5C). When the interval was shorter than 5 hours each new injection resulted in a smaller response than the preceding one (Figure $5 \mathrm{~B}$ ). A very rapid decline in sweating rate was seen following the constant intradermal infusion (Figure 5A).

Sweat glands which had been rendered refractory to Mecholyl showed no response to the stimulus of general heat. Sweat collection chambers were glued to each of two sites on each forearm. At room temperature and with the subject at rest, four intradermal injections of Mecholyl were given at 40-minute intervals at each of the collection sites on the left forearm. Immediately thereafter the subject entered the hot room where he remained for a period of 80 minutes. The rates of sweating from all four sites were measured and compared.

The results, shown in Figure 6, demonstrate that the sweat glands on the left forearm, which had been rendered refractory to Mecholyl showed little response to the stimulus of general heat as compared to the untreated glands on the right forearm.

After a single injection of Mecholyl a period of 5 to 6 hours was required for complete restoration of glandular power. Sweat collection cham-

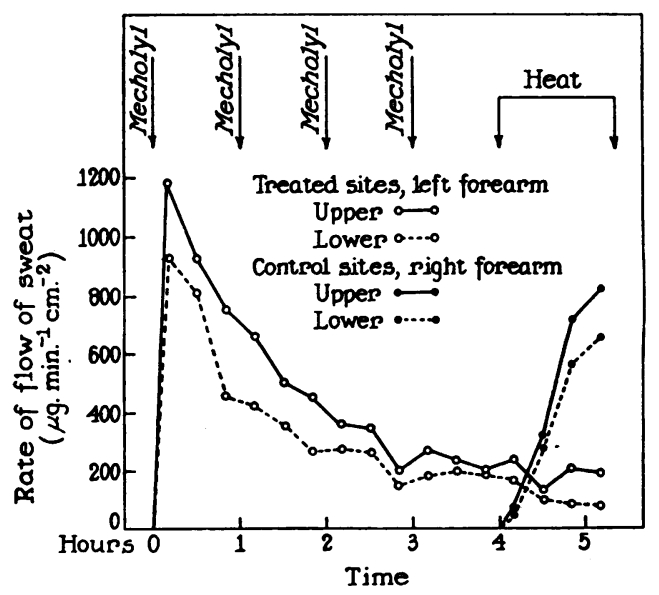

Fig. 6. Comparison of the Responses to General heat at Two Sites on the Left Forearm, Which Have Been Pretreated by Repeated Injections of Mecholyl, with the Responses at Symmetrical Sites on the Right Forearm Which Have Remained UNTREATED 
bers were glued to two sites on each forearm. Mecholyl, $2 \mathrm{mg}$. in $0.5 \mathrm{ml}$. isotonic saline, was injected at all four sites and the rate of sweat secretion measured in six 20-minute periods. Injections of Mecholyl at all four sites were repeated after two hours and the rate of sweat secretion was again measured in six 20 -minute periods. This experiment was repeated on each of the three following days, using the same four sites on the forearms but extending the intervals between the two injections of Mecholyl to 3 hours on the first day, 4 hours on the next and 5 hours on the last day. The total output of sweat in the six periods following the second injection of Mecholyl, $Q_{2}$, was compared to the total output of sweat in the six periods following the first injection of Mecholyl, $Q_{1}$. For the four sites the ratios, $Q_{2} / Q_{1}$, averaged $0.44,0.76,0.86$, and 0.93 when the intervals between the first and second injection were $2,3,4$, and 5 hours, respectively (Figure 7).

\section{DISCUSSION}

Apparently sweating can continue indefinitely at the same rate only as long as the demand upon the secretory mechanism does not exceed simultaneous processes that operate to restore secretory function. Whenever the demand upon the secre-

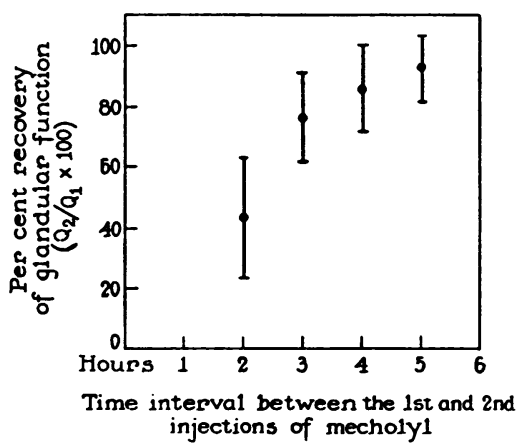

Fig. 7. The Recovery of Glandular Function DeTERMINEd BY Two Identical INJections OF Mecholyl Grven 2, 3, 4, and 5 Hours Apart

The total output of sweat following the second injection, $Q_{2}$, has been calculated as a percentage of the total output of sweat following the initial injection, $Q_{1}$. The points represent mean values determined from four sites; the vertical lines represent the corresponding standard deviations.

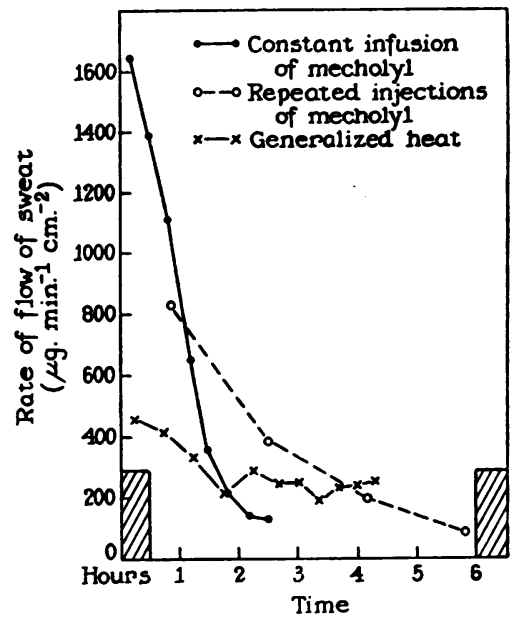

Fig. 8. The Decline in the Rate of Sweating Following a CONSTANT INTRADERMAL INFUSION OF Mecholyl, Repeated Injections of Mecholyl at 100Minute Intervals and the Stimulus of Heat

The closed circles represent the sweating rates obtained during infusion of Mecholyl at the rate of $50 \mathrm{\mu g}$. per minute. The open circles represent mean sweating rates in each of the 100-minute periods in Figure 5B. The two bars represent a theoretical maximal rate at which sweating may continue indefinitely without evidence of fatigue (calculated from the mean total sweat output of the two 120-minute periods in Figure 5C divided by 300 minutes.)

tory mechanism exceeds restorative functions, the rate of sweating will decrease. This phenomenon is indicated in Figure 8. The curves show the characteristic decrease in sweating rate with time following each of two different intensities of stimulation with Mecholyl and following exposure to a hot environment. The constant intense stimulation of the sweat glands by intradermal infusion of Mecholyl is followed by more rapid diminishing of the rate of flow of sweat than the less intense stimulation by repetitive intradermal injections of Mecholyl or the still less intense reflex stimulation of heat. Following each of these different qualities of stimulation the sweating rate reaches an early maximum after which it decreases exponentially with a half time of 40,90 , and $180 \mathrm{~min}$ utes depending on the intensity of stimulation. A theoretical maximum rate of flow at which sweating may continue indefinitely was calculated by dividing the total output of sweat obtained following stimulation of the glands with a stand- 
ard dose of Mecholyl by the minimum of time required for full recovery of secretory function as judged by the ability of the same glands to reproduce quantitatively the initial response when challenged with an identical injection of Mecholyl (Figure 8).

Previous reports (1-3) on a decrease in the rate of sweating following a prolonged exposure to a hot environment, have been confirmed by the findings of the present investigation. The results indicate that the decrease in sweating rate is primarily due to a decrease in the activity of each sweat gland as a functional unit.

It is shown that the same stimulus will elicit a more vigorous response in resting glands than in glands that have been exhausted by previous function. This is true for the physiological stimulus of environmental heat (Figure 4) as well as for the pharmacological stimulus of a cholinergic drug (Figure 3). Likewise a decreased reactivity to the physiological thermal stimulus is seen as well in glands that have been exhausted by previous reflex sweating (Figures 1 and 4 ) as in glands that have been exhausted by intensive sweating due to repeated injections of cholinergic drug (Figures $5 \mathrm{~B}$ and 6 ). These findings indicate that the decrease in sweating rate on prolonged reflex sweating is primarily due to an exhaustion of the secretory mechanism of the sweat gland, and not to a decrease in nervous stimulation. The fact that previously rested and previously functioning glands react differently to the same stimulus (Figure 4) excludes the possibility that the drop in sweating rate may be mediated by humoral factors.

Therefore, it seems reasonable to speak of "fatigue" of the sweat glands as the primary cause of the decrease in sweating rate noted on prolonged exposures to intense heat. The experiments with cholinergic stimulation suggest that the degree of fatigue of the glands becomes greater the more the demand upon the secretory mechanism exceeds the simultaneous restorative capacity. Thus fatigue of the sweat glands and defective restoration of secretory activity may well be the primary factors involved in the induction, perpetuation, and progression of human heat stroke.

\section{SUMMARY}

Earlier work has shown that the rate of sweat secretion decreased during prolonged exposures to environmental temperatures greater than $40^{\circ} \mathrm{C}$. In the present investigation this observation has been confirmed and extended by a study of the activity of sweat glands in response to local chemical stimulation as well as to general heating of the body. A fall in sweating rate of from 30 to 60 per cent of maximum flow has been shown to occur during the third to fifth hour of exposure to an environment of $40^{\circ}$ to $45^{\circ} \mathrm{C}$., relative humidity 60 to 90 per cent. Quantitative collections of sweat and registrations of the number of functioning glands from the same area of skin indicate that this response is due to a decrease primarily in the activity of each glandular unit and secondarily in the number of functioning units. The relative activities $^{1}$ of the sweat glands have been shown to remain unchanged during exposure to heat, indicating that the absolute decline in function of any single gland is proportional to its original or maximal functional capacity.

Repeated intradermal injections or a constant infusion of $\beta$-methylacetylcholine hydrochloride, Mecholyl, evoked decreasing outputs of sweat until a refractory state was reached; as in the case of general reflex sweating the decrease in secretion rate was due chiefly to decline in the flow per gland, and less to decline in the number of functioning glands. The time needed for recovery of glandular function following a single maximal stimulation with Mecholyl proved to be 5 to 6 hours.

Sweat glands which had been rendered refractory to Mecholyl showed no response to the stimulus of general heat; conversely, the output of sweat following intradermal injection of Mecholyl was diminished by preliminary reflex sweating.

\section{CONCLUSIONS}

These results suggest that the decrease in reflex sweating produced by environmental heat is due to fatigue of the glandular units and not to decreased central nervous stimulation. Apparently sweating can continue indefinitely at the 
same rate only if the demand on the secretory mechanism does not exceed simultaneous processes that operate to restore secretory function. When the demand upon the secretory mechanism exceeds the capacity for restoration of function, the sweating rate decreases.

\section{REFERENCES}

1. Wolkin, J., Goodman, J. I., and Kelley, W. E., Failure of the sweat mechanism in the desert. J. A. M. A., 1944, 124, 478.
2. Ladell, W. S. S., Changes in the chloride concentration of sweat with acclimatization. Biochem. J., 1945, 39, xlvii.

3. Gerking, S. D., and Robinson, S., Decline in the rates of sweating of men working in severe heat. Am. J. Physiol., 1946, 147, 370.

4. Schwartz, I. L., Thaysen, J. H., and Dole, V. P., Urea excretion in human sweat as a tracer for movement of water within the secreting gland. J. Exper. Med., 1953, 97, 429.

5. Dole, V. P., and Thaysen, J. H., Variation in the functional power of human sweat glands. J. Exper. Med., 1953, 98, 129.

\section{SPECIAL NOTICE TO SUBSCRIBERS}

Post Offices will no longer forward the Journal when you move.

Please notify The Journal of Clinical Investigation, Business Office, 622 West 168th Street, New York 32, N. Y. at once when you have a change of address, and do not omit the zone number if there is one. 